\title{
Statin-induced apoptosis via the suppression of ERK1/2 and Akt activation by inhibition of the geranylgeranyl-pyrophosphate biosynthesis in glioblastoma
}

Masashi Yanae ${ }^{1,2}$, Masanobu Tsubaki', Takao Satou ${ }^{3}$, Tatsuki Itoh ${ }^{3}$, Motohiro Imano ${ }^{4}$, Yuzuru Yamazoe ${ }^{5}$ and Shozo Nishida ${ }^{*}$

\begin{abstract}
Background: Statins are inhibitors of 3-hydroxy-3-methylglutaryl-coenzyme A reductase, the rate-limiting enzyme in cholesterol synthesis. The inhibition of this key enzyme in the mevalonate pathway leads to suppression of cell proliferation and induction of apoptosis. However, the molecular mechanism of apoptosis induction by statins is not well understood in glioblastoma. In the present study, we attempted to elucidate the mechanism by which statins induce apoptosis in C6 glioma cells.

Methods: The cytotoxicity of statins toward the C6 glioma cells were evaluated using a cell viability assay. The enzyme activity of caspase-3 was determined using activity assay kits. The effects of statins on signal transduction molecules were determined by western blot analyses.

Results: We found that statins inhibited cell proliferation and induced apoptosis in these cells. We also observed an increase in caspase-3 activity. The apoptosis induced by statins was not inhibited by the addition of farnesyl pyrophosphate, squalene, ubiquinone, and isopentenyladenine, but by geranylgeranyl-pyrophosphate (GGPP). Furthermore, statins decreased the levels of phosphorylated extracellular signal-regulated kinase 1/2 (ERK1/2) and Akt.

Conclusions: These results suggest that statins induce apoptosis when GGPP biosynthesis is inhibited and consequently decreases the level of phosphorylated ERK1/2 and Akt. The results of this study also indicate that statins could be used as anticancer agents in glioblastoma.
\end{abstract}

Keywords: statins, C6 glioma, ERK, Akt

\section{Background}

Glioblastoma is the most common type of malignant brain tumor and its prognosis is very poor. Surgical resection and chemotherapy are common treatments [1]. Despite recent advances in the understanding of the molecular mechanism of tumorigenesis, the outcome of malignant glioma remains poor [2]. Thus, it is imperative that new effective forms of therapy are developed for its treatment.

\footnotetext{
*Correspondence: nishida@phar.kindai.ac.jp

'Division of Pharmacotherapy, Kinki University School of Pharmacy, Kowakae, Higashi-Osaka 577-8502, Japan

Full list of author information is available at the end of the article

Statins are cholesterol-lowering agents that inhibit 3hydroxy-3-methylglutaryl-coenzyme A (HMG-CoA) reductase, which catalyzes the conversion of HMG-CoA into mevalonate. Mevalonate is converted into farnesyl pyrophosphate (FPP) or geranylgeranyl pyrophosphate (GGPP) that can be anchored onto intracellular proteins through prenylation, thereby ensuring the relocalization of the target proteins in the cell membranes [3-5]. Inhibition of HMG-CoA reductase results in alteration of the prenylation of small $G$ proteins such as Ras, which regulates cell growth and survival via the downstream signaling pathways [3-5]. Accordingly, inhibition of HMG-CoA reductase by statins was found to trigger 
apoptosis in several cancer cells [3-5]. We recently showed that statins decreased the activation of the Ras/ extracellular regulated kinase $1 / 2($ ERK1/2) pathway and Ras/phosphoinositol-3 kinase/Akt pathway $[3,4]$. In malignant glioma cells, statins induce apoptosis by the activation of c-Jun N-terminal kinase $1 / 2$ (JNK1/2) or by increasing the expression of Bim [6,7]. However, several aspects of the mechanism by which statins induce apoptosis in glioma cells remain unclear. In the present study, we investigated the mechanism by which statins induce apoptosis in rat C6 glioma cells.

\section{Materials and methods Materials}

Mevastatin was purchased from Sigma (St. Louis, MO, USA), fluvastatin from Calbiochem (San Diego, CA, USA), and simvastatin from Wako (Osaka, Japan). These reagents were dissolved in dimethyl sulfoxide (DMSO) and filtered through syringe filters $(0.45 \mu \mathrm{m}$; Iwaki Glass, Tokyo, Japan). The dissolved reagents were resuspended in phosphate-buffered saline (PBS, $\mathrm{pH} 7.4$ ) and used in the various assays described below.

Mevalonic acid lactone (MVA), FPP, GGPP, squalene, ubiquinone, isopentenyladenine, and dolichol were purchased from Sigma. These reagents were dissolved in DMSO. These dissolved reagents were then resuspended in PBS (0.05 M; pH 7.4) and filtered through syringe filters $(0.45 \mu \mathrm{m}$; Iwaki Glass) before use.

\section{Cell culture}

C6 glioma cells were supplied by Dr. Takashi Masuko (Kinki University, Osaka, Japan) and cultured in Dulbecco's Modified Eagle's Medium (Sigma) supplemented with $10 \%$ fetal calf serum (FCS) (Gibco, Carlsbad, CA, USA), $100 \mu \mathrm{g} / \mathrm{ml}$ penicillin (Gibco), $100 \mathrm{U} / \mathrm{ml}$ streptomycin (Gibco), and 25 mM HEPES ( $\mathrm{pH} 7.4$; Wako) in an atmosphere containing 5\% $\mathrm{CO}_{2}$. U251MG cells were provided by Health Science Research Resources Bank (Osaka, Japan) and cultured in minimum essential medium (Sigma) supplemented with $10 \%$ fetal calf serum (Gibco), $100 \mu \mathrm{g} / \mathrm{ml}$ penicillin (Gibco), $100 \mathrm{U} / \mathrm{ml}$ streptomycin (Gibco), and $25 \mathrm{mM}$ HEPES (pH 7.4; Wako) in an atmosphere containing $5 \% \mathrm{CO}_{2}$.

\section{Cell viability}

Cell viability was quantified by using a trypan blue dye assay. The cells (2000 cells/well) were plated in 96well plates and incubated with various concentrations of mevastatin, fluvastatin, and simvastatin for 24,48 , and $72 \mathrm{~h}$. After incubation, the cells were stained with trypan blue, and the number of stained cells was counted.

\section{Measurement of caspase- 3 proteolytic activity}

We measured the caspase-3-like enzyme activity by monitoring proteolytic cleavage of the fluorogenic substrate Asp-Glu-Val-Asp-7-Amino-4-trifluoromethylcoumarin (DEVD-AFC) using the ApoTarget caspase-3 protease assay kit (BioSource International Inc., Camarillo, CA). The C6 glioma cells were incubated with or without mevastatin, fluvastatin, and simvastatin for $24 \mathrm{~h}$. The cells were then collected, washed in PBS, and lysed in the lysis buffer provided in the aforementioned kit. The assay was performed by incubating a solution of cell lysates containing a $50 \mu \mathrm{M}$ substrate at $37^{\circ} \mathrm{C}$ for 1 h. We fluorometrically measured the release of 7 amino-4-methylcoumarin from the substrate by using a fluorescence spectrophotometer (F-4010, Hitachi) at an emission wavelength of $505 \mathrm{~nm}$ and an excitation wavelength of $400 \mathrm{~nm}$. Caspase- 3 activity (measured on the basis of proteolytic cleavage of the caspase- 3 substrate DEVD-AFC) was expressed in terms of change in substrate concentration (in $\mathrm{pM}$ ) per $\mathrm{h}$ per $\mathrm{mg}$ of protein, after correction for the protein content of the lysates; the protein content of the cell lysate was determined by using the bicinchoninic acid (BCA) protein assay kit (Pierce, Rockford, IL, USA).

\section{Western blotting}

C6 glioma cells treated with statins were lysed with a lysis buffer containing $20 \mathrm{mM}$ Tris- $\mathrm{HCl}$ (pH 8.0), 150 $\mathrm{mM} \mathrm{NaCl}, 2$ mM EDTA, $100 \mathrm{mM} \mathrm{NaF}, 1 \% \mathrm{NP}-40,1$ $\mu \mathrm{g} / \mathrm{ml}$ leupeptin, $1 \mu \mathrm{g} / \mathrm{ml}$ antipain, and $1 \mathrm{mM}$ phenylmethylsulfonyl fluoride. The protein content in the cell lysates was determined using a BCA protein-assay kit. The extracts (40 $\mu \mathrm{g}$ protein) were fractionated on polyacrylamide-SDS gels and transferred to polyvinylidene difluoride (PVDF) membranes (Amersham, Arlington Heights, IL, USA). The membranes were blocked with a solution containing 3\% skim milk and incubated overnight at $4{ }^{\circ} \mathrm{C}$ with each of the following antibodies: antiphospho-ERK1/2 (Thr202/Tyr204), anti-phospho-Akt (Ser473), anti-phospho-JNK1/2 (Thr183/Tyr185), antiERK1/2, anti-Akt, and anti-JNK1/2 (Cell Signaling Technology, Beverly, MA, USA). Subsequently, the membranes were incubated for $1 \mathrm{~h}$ at room temperature with horseradish peroxidase-coupled anti-rabbit IgG sheep antibodies (Amersham). The reactive proteins were visualized using ECL-plus (Amersham) according to the manufacturer's instructions.

\section{Statistical analysis}

All results are expressed as mean \pm SD of several independent experiments. Multiple comparisons of the data were performed by analysis of variance (ANOVA) with Dunnett's test. $P$ values less than $5 \%$ were regarded as significant. 


\section{Results}

Effects of statins on C6 glioma cell proliferation and viability

To examine the cytotoxic effects of mevastatin, fluvastatin, or simvastatin on C6 glioma cells, C6 glioma cell proliferation was assessed in the presence of mevastatin (1-10 $\mu \mathrm{M})$, fluvastatin (1-10 $\mu \mathrm{M})$, or simvastatin (2.5-20 $\mu \mathrm{M})$. We found that statins inhibited the C6 glioma cell proliferation in a concentration- and time-dependent manner (Figure $1 \mathrm{~A}-\mathrm{C}$ ).

We also determined the cell survival rate, which was defined as the number of living cells at 24, 48, and $72 \mathrm{~h}$ after exposure to these agents at various concentrations compared with the number of live control $(0.1 \%$ DMSO-treated) cells. The survival rates on exposure to $1,2.5,5$, and $10 \mu \mathrm{M}$ of mevastatin were $83.82 \%, 58.23 \%$, $4.41 \%$, and $0.52 \%$, respectively, at $72 \mathrm{~h}$ (Figure 1D). Thus, the number of C6 glioma cells significantly decreased at $72 \mathrm{~h}$ after the administration of 5 and 10 $\mu \mathrm{M}$ mevastatin. The survival rates on exposure to $1,2.5$, 5 , and $10 \mu \mathrm{M}$ of fluvastatin were $69.70 \%, 54.71 \%, 9.71 \%$, and $0.88 \%$, respectively, at $72 \mathrm{~h}$ (Figure $1 \mathrm{E}$ ). Thus, the number of C6 glioma cells significantly decreased at 72 $\mathrm{h}$ after the administration of 5 and $10 \mu \mathrm{M}$ fluvastatin. The survival rates on exposure to $2.5,5,10$, and $20 \mu \mathrm{M}$ of simvastatin were $96.17 \%, 53.82 \%, 1.76 \%$, and $0.49 \%$, respectively, at $72 \mathrm{~h}$ (Figure $1 \mathrm{~F}$ ). Thus, the number of C6 glioma cells significantly decreased at $72 \mathrm{~h}$ after the administration of 10 and $20 \mu \mathrm{M}$ simvastatin. On the basis of these results, 5,5 , and $10 \mu \mathrm{M}$ were determined to be the cytotoxic concentrations of mevastatin, fluvastatin, and simvastatin, respectively.

To examine the cytotoxic effects of mevastatin, fluvastatin, or simvastatin on U251MG cells, the survival of these cells was assessed in the presence of mevastatin (1-10 $\mu \mathrm{M})$, fluvastatin (1-10 $\mu \mathrm{M})$, or simvastatin (2.5-20 $\mu \mathrm{M})$. We determined the cell survival rate, which was defined as the ratio of the number of living cells after 24,48 , and $72 \mathrm{~h}$ of incubation with $1,2.5,5,10 \mu \mathrm{M}$ mevastatin, $1,2.5,5$, and $10 \mu \mathrm{M}$ fluvastatin or $2.5,5,10$, and $20 \mu \mathrm{M}$ simvastatin to the number of living cells in the control (0.1\% DMSO-treated) samples. The survival rates on exposure to $1,2.5,5$, and $10 \mu \mathrm{M}$ of mevastatin were $81.44 \%, 58.41 \%, 31.81 \%$, and $16.93 \%$, respectively, at $72 \mathrm{~h}$ (Figure 2A). Thus, the number of U251MG cells significantly decreased at $72 \mathrm{~h}$ after the administration of 5 and $10 \mu \mathrm{M}$ mevastatin. The survival rates on exposure to $1,2.5,5$, and $10 \mu \mathrm{M}$ of fluvastatin were $63.37 \%$, $53.71 \%, 25.45 \%$, and $24.08 \%$, respectively, at $72 \mathrm{~h}$ (Figure 2B). Thus, the number of U251MG cells significantly decreased at $72 \mathrm{~h}$ after the administration of 5 and 10 $\mu \mathrm{M}$ fluvastatin. The survival rates on exposure to $2.5,5$, 10 , and $20 \mu \mathrm{M}$ of simvastatin were $65.57 \%, 57.59 \%$, $25.11 \%$, and $21.87 \%$, respectively, at $72 \mathrm{~h}$ (Figure $2 \mathrm{C}$ ).
Thus, the number of U251MG cells significantly decreased at $72 \mathrm{~h}$ after the administration of 10 and 20 $\mu \mathrm{M}$ simvastatin.

\section{Statins-mediated activation of caspase-3}

The cytotoxic effects of statins on C6 glioma cells were attributed to the induction of apoptosis, as demonstrated by the results of the following biochemical assays. We investigated the involvement of statins in caspase- 3 activation. Caspase- 3 activity was measured at $24 \mathrm{~h}$ after the addition of $5 \mu \mathrm{M}$ mevastatin, $5 \mu \mathrm{M}$ fluvastatin, $10 \mu \mathrm{M}$ simvastatin to the C6 glioma cells. We observed that the addition of statins resulted in a marked increase in caspase- 3 activity in comparison with that in the control (0.1\% DMSO-treated cells) (Figure $3 \mathrm{~A})$.

\section{Combined effects of intermediate in the mevalonate pathway on the apoptosis-inducing effect of statins}

To study the combined effects of MVA, FPP, GGPP, squalene, isopentenyladenine, dolichol, and ubiquinone on the apoptosis-inducing effect of statins, C6 glioma cells were pre-administered $1 \mathrm{mM}$ MVA, $10 \mu \mathrm{M}$ FPP, $10 \mu \mathrm{M}$ GGPP, $300 \mu \mathrm{M}$ squalene, $30 \mu \mathrm{M}$ isopentenyladenine, $30 \mu \mathrm{M}$ dolichol, and $30 \mu \mathrm{M}$ ubiquinone. Mevastatin, fluvastatin, or simvastatin were added to cell suspensions to a concentration of 5,5 , or $10 \mu \mathrm{M}$. After $72 \mathrm{~h}$, the cell viability was measured by the trypan blue dye method described above. The statins did not show any significant difference in cell viability in the presence of FPP, squalene, isopentenyladenine, dolichol, and ubiquinone. However, pretreatment with MVA and GGPP caused the statin-induced apoptosis to be significantly inhibited (Figure 3B-D).

\section{Statin-induced decrease in the expressions of phosphorylated ERK1/2 and Akt}

To identify the molecules involved in statin-induced apoptosis, we investigated the Ras downstream cascade that statins may inhibit in order to induce apoptosis. Statins inhibited the expression of phosphorylated ERK1/2 and Akt, as downstream Ras. There was no substantial change in the level of phosphorylated JNK $1 / 2$ in the statins-treated cells relative to that of the control cells (0.1\%DMSO-treated cells) (Figure 4A).

We then administered statins in combination with MVA, FPP, or GGPP to investigate whether the inhibition of ERK1/2 and Akt activation in C6 glioma cells was due to the inhibitory action of statins on FPP or GGPP biosynthesis via their mechanism of action. Statins inhibited the activation of ERK1/2 and Akt, whereas in combination with GGPP, the activation levels of these signal transduction molecules were restored to the degree observed in control cells (0.1\% DMSO-treated) 


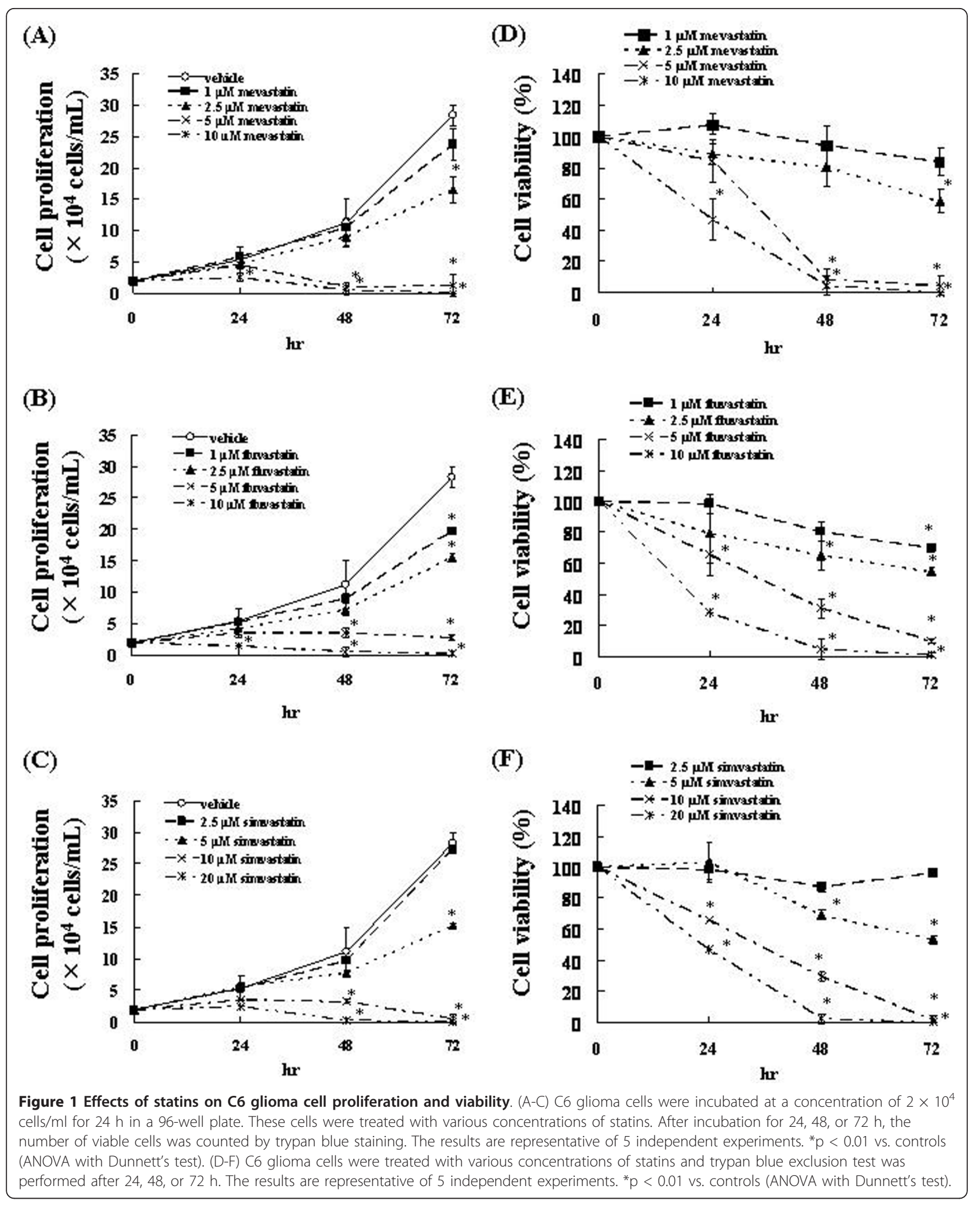



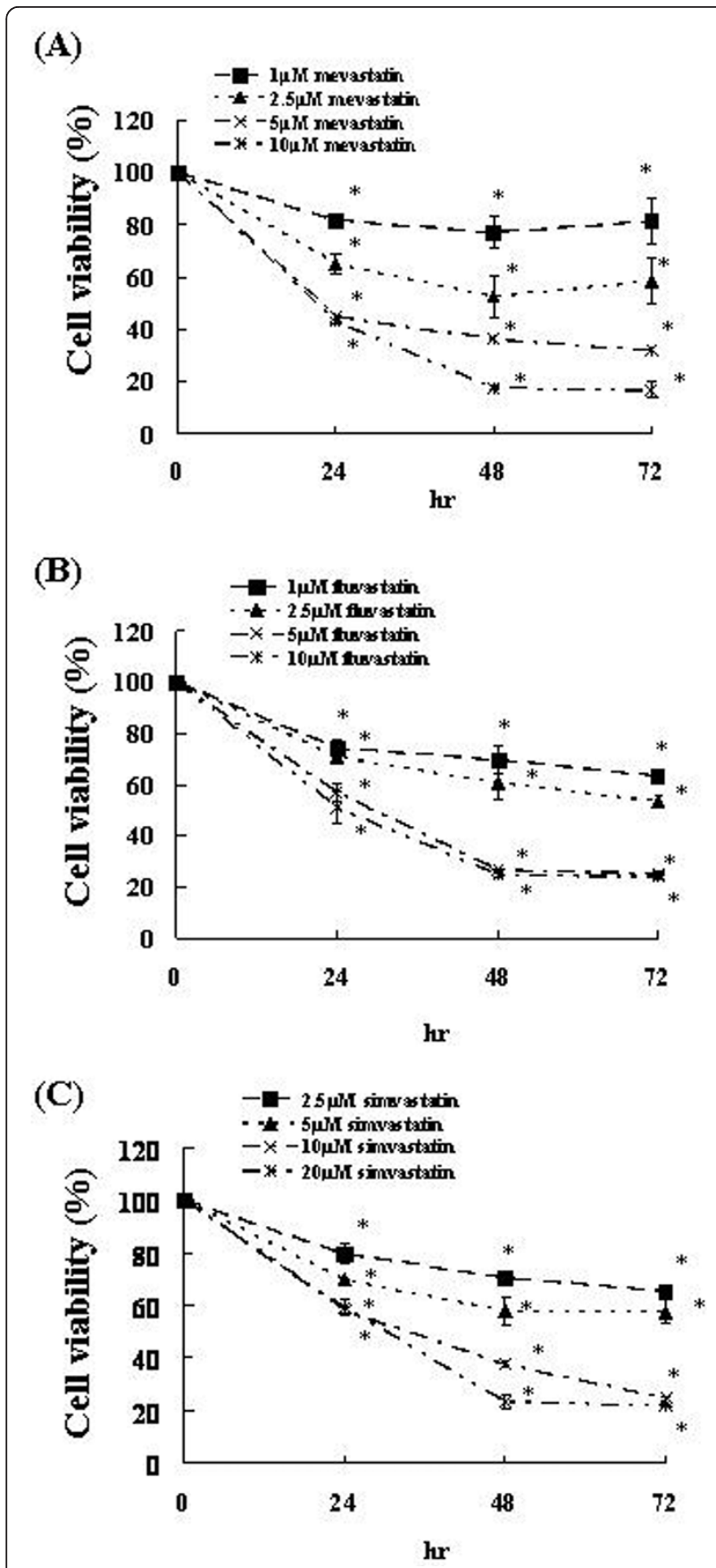

Figure 2 Effects of statins on U251MG cell viability. U251MG cells were treated with various concentrations of statins and trypan blue exclusion test was performed after 24,48 , or $72 \mathrm{~h}$. The results are representative of 5 independent experiments. ${ }^{*} p<0.01$ vs. controls (ANOVA with Dunnett's test).

(Figure 4B). These observations suggest that the inhibition of ERK1/2 and Akt activation in C6 glioma cells treated with statins was due to the inhibition of GGPP biosynthesis.

\section{Discussion}

In the present study, we have demonstrated that statins inhibit C6 glioma cell proliferation. We have also found that statins induce apoptosis by activation of caspase-3 through inhibition of GGPP biosynthesis. It has been reported that statins inhibit prenylation of small $G$ proteins by suppressing the production of GGPP $[4,8]$. Lovastatin is known to inhibit the mevalonic acid and MAPK pathways, thereby inducing apoptosis $[9,10]$. It has been reported that the mechanism of action is inhibition of GGPP biosynthesis [10,11]. These findings suggest that statins induce apoptosis by activation of caspase-3 through suppression of GGPP biosynthesis.

GGPP is an important membrane-anchoring molecule of Ras protein. A shortage of GGPP facilitates dissociation of Ras from the inner surface of the membrane, and decreases the Ras-mediated growth signal, thereby inhibiting cellular proliferation [12,13]. Our results clearly demonstrate that statins induce a decrease in ERK1/2 and Akt activation of Ras downstream, but the activation of JNK1/2 was not altered. We previously reported that mevastatin induces a decrease in phosphorylated ERK [3]. We also demonstrated that fluvastatin and simvastatin decrease the activation of ERK $1 / 2$ Akt [4]. These findings are in agreement with the results of the present study and indicate that statins induce apoptosis via suppression of Ras/ERK and Ras/Akt pathways in our experimental model (Figure 5).

As described above, statins are known to affect the functions of Ras by inhibiting prenylation through the inhibition of GGPP synthesis; this enables localization of Ras at the plasma membrane [14,15]. Ras is involved in the activation of the MEK/ERK and PI3K/Akt pathways $[14,16]$, suggesting the mechanism of action of statins.

The treatment of C6 glioma cells with $5 \mu \mathrm{M}$ mevastatin, $5 \mu \mathrm{M}$ fluvastatin or $10 \mu \mathrm{M}$ simvastatin for $72 \mathrm{~h}$ in vitro inhibited GGPP synthesis. We also found that the treatment of C6 glioma cells with $2.5 \mu \mathrm{M}$ mevastatin, 1 $\mu \mathrm{M}$ fluvastatin or $5 \mu \mathrm{M}$ simvastatin for $72 \mathrm{~h}$ inhibited cell proliferation. The peak plasma concentrations of fluvastatin or simvastatin achieved with standard doses were $\leq 1 \mu \mathrm{M}$ or $2.7 \mu \mathrm{M}$, respectively $[17,18]$. It has been reported that peak plasma concentration of fluvastatin achieved with high dose were $\leq 2 \mu \mathrm{M}$ [19]. These findings indicate that $2 \mu \mathrm{M}$ and $2.5 \mu \mathrm{M}$ of fluvastatin and simvastatin, respectively, are within the peak plasma values of fluvastatin or simvastatin that are likely to be achieved in vivo. In addition, we found that $2.5 \mu \mathrm{M}$ fluvastatin induced the apoptosis. Therefore, fluvastatin may be potentially useful as anti-cancer agents in the treatment of glioblastoma. 
(A)

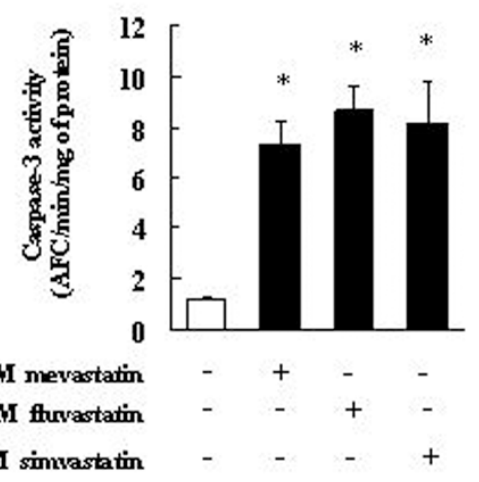

(C)

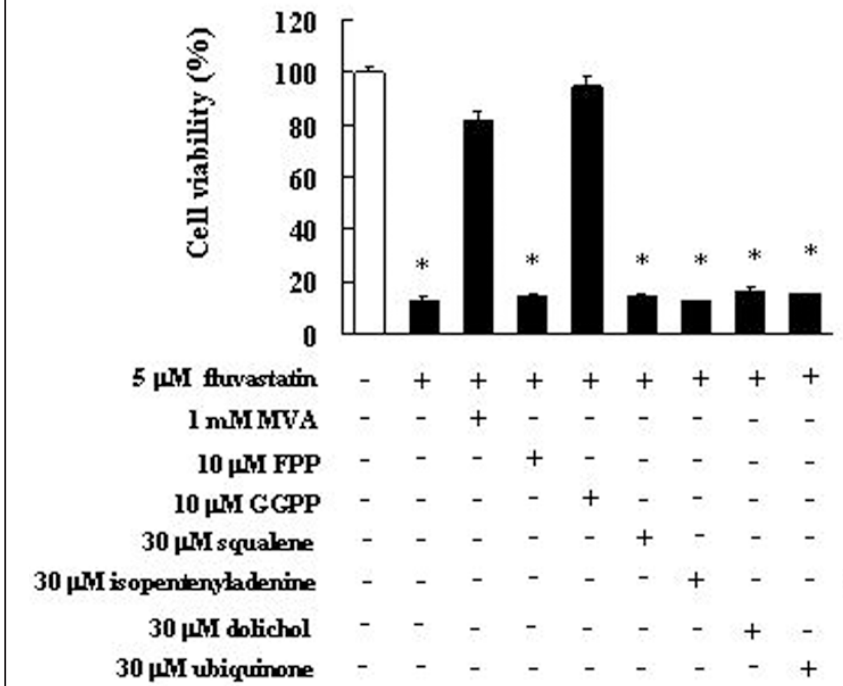

(B)
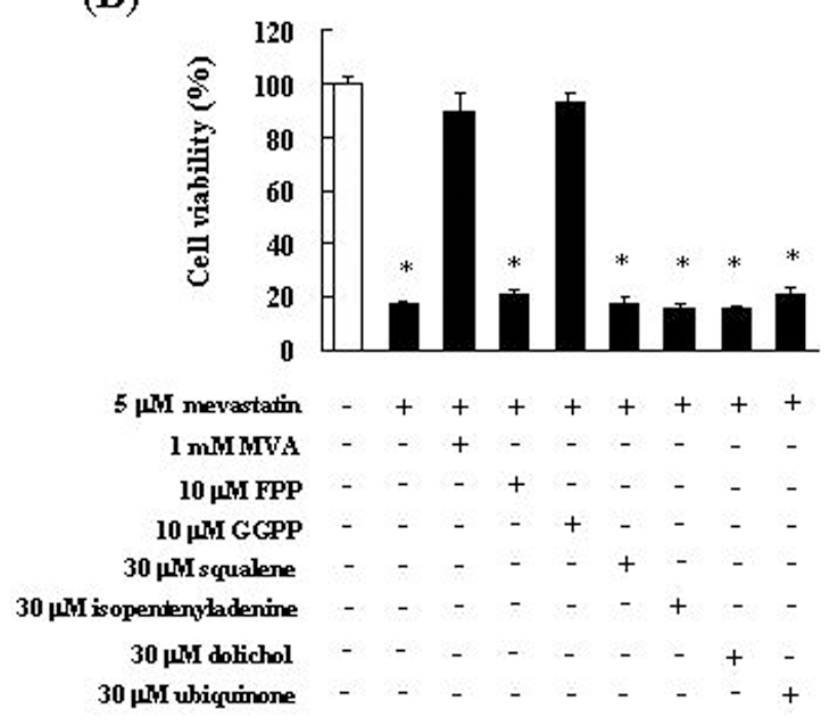

(D)

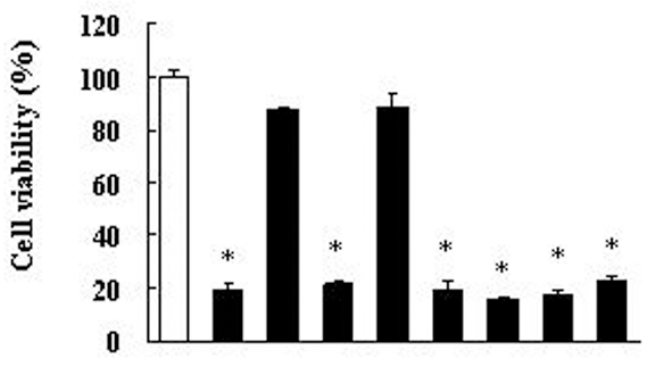

$10 \mu$ simvastatin -++++++++

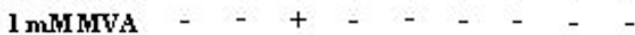

$10 \mu \mathrm{MFPP}-\mathrm{-}-\mathrm{+}-\mathrm{-}-\mathrm{-}-$

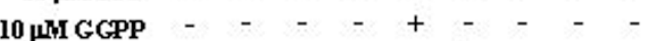

$30 \mu$ Msqualene - $\quad-\quad-\quad+\quad-\quad-$

$30 \mu \mathrm{M}$ isopentenyladenine - $\quad-\quad-\quad+-$

$30 \mu \mathrm{M}$ dolichol $-\quad-\quad-\quad-\quad+-$

$30 \mu$ Mbiquinone $\quad-\quad-\quad-\quad-\quad-\quad+$

Figure 3 Inhibition of statin-induced apoptosis in C6 glioma cells by intermediates of the mevalonate pathway. (A) Induction of caspase-3-like activity associated with statin-induced cell death. Caspase-3 activity is expressed as pM of proteolytic cleavage of the caspase-3 substrate Asp-Glu-Val-Asp-7-Amino-4-trifluoromethylcoumarin (DEVD-AFC) per $\mathrm{h}$ per $\mathrm{mg}$ of protein. The results are representative of 5 independent experiments. ${ }^{*} \mathrm{p}<0.01$ vs. controls (ANOVA with Dunnett's test). (B-D) C6 glioma cells were pretreated with $1 \mathrm{mM}$ mevalonic acid lactone (MVA), $10 \mu \mathrm{M}$ farnesyl pyrophosphate (FPP), $10 \mu \mathrm{M}$ geranylgeranyl pyrophosphate (GGPP), $30 \mu \mathrm{M}$ squalene, $30 \mu \mathrm{M}$ isopentenyladenine, $30 \mu \mathrm{M}$ ubiquinone, or $30 \mu \mathrm{M}$ dolichol for $4 \mathrm{~h}$ and then treated with (B) $5 \mu \mathrm{M}$ mevastatin, (C) $5 \mu \mathrm{M}$ fluvastatin, or (D) $10 \mu \mathrm{M}$ simvastatin for $72 \mathrm{~h}$. These results are representative of 5 independent experiments. ${ }^{*} p<0.01$ vs. the controls (ANOVA with Dunnett's test).

\section{Conclusion}

In conclusion, these results provide evidence of the specific molecular pathways via which statins induce apoptosis by increasing the activation of caspase-3 through inhibition of Ras/ERK and Ras/Akt pathways.
The findings indicate that statins may act more effectively on tumors that have spread on Ras-variable tumors. This further suggests that statins may be potentially useful as anti-cancer agents in the treatment of glioblastoma. 
(A)

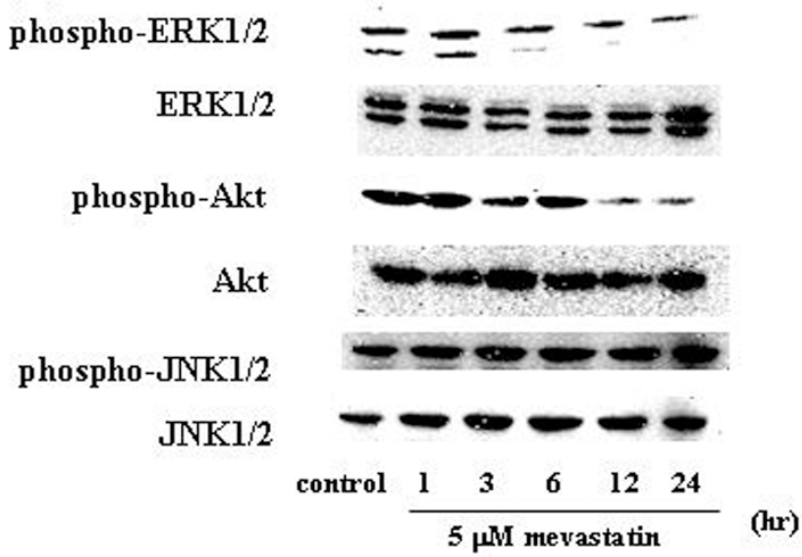

phospho-ERKl/2 = =

$\mathrm{ERKl} / 2 \quad \Rightarrow z=\approx=$

phospho-Akt

Akt

phospho-JNKl/2

JNK1/2

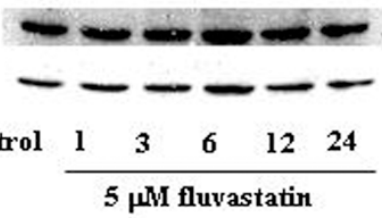

(hr)
(B)

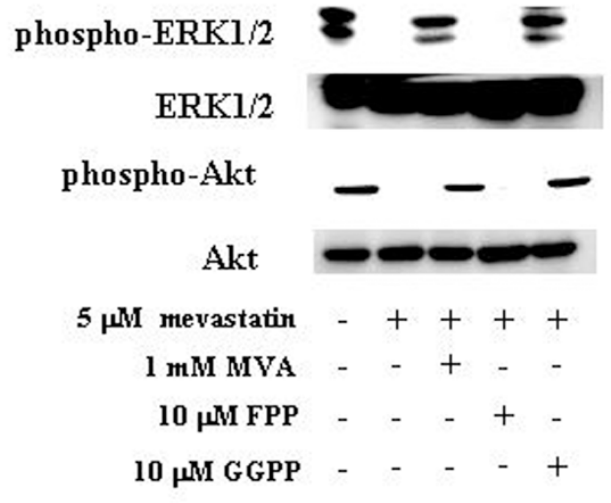

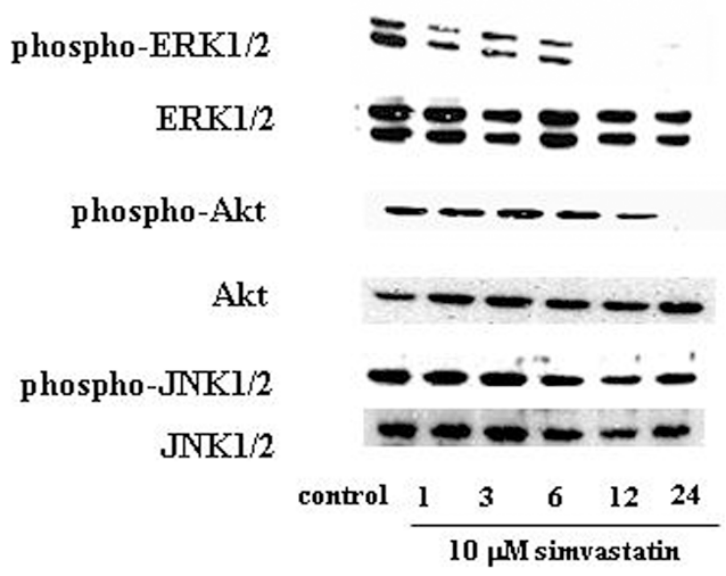

(hr)

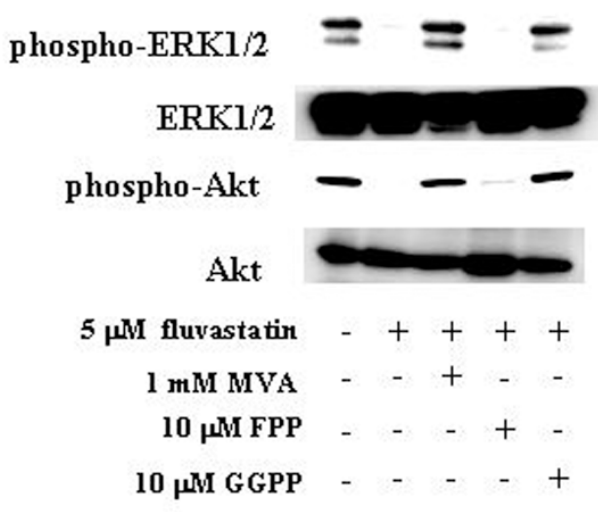

Figure 4 Statins specifically suppress the activation of Ras/extracellular signal-regulated kinase (ERK) and Ras/Akt pathways in C6 glioma cells. (A) C6 glioma cells were treated with $5 \mu \mathrm{M}$ mevastatin, $5 \mu \mathrm{M}$ fluvastatin, or $10 \mu \mathrm{M}$ simvastatin for 1, 3, 6, 12, or $24 \mathrm{~h}$. Control cells were treated with $0.1 \%$ DMSO and cultured in serum-containing medium for $24 \mathrm{~h}$. Whole-cell lysates were generated and immunoblotted with antibodies against phosphorylated ERK1/2 (phospho-ERK1/2), phosphorylated Akt (phospho-Akt), phosphorylated c-Jun N-terminal kinase $1 / 2$ (phospho-JNK1/2), ERK1/2, Akt, and JNK1/2. (B) ERK1/2 and Akt activation in C6 cells to which statins were administered with or without the addition of MVA, FPP, and GGPP. Phospho-ERK1/2, phospho-Akt, ERK1/2, and Akt levels were determined by immunoblotting analysis of the whole-cell lysate. 


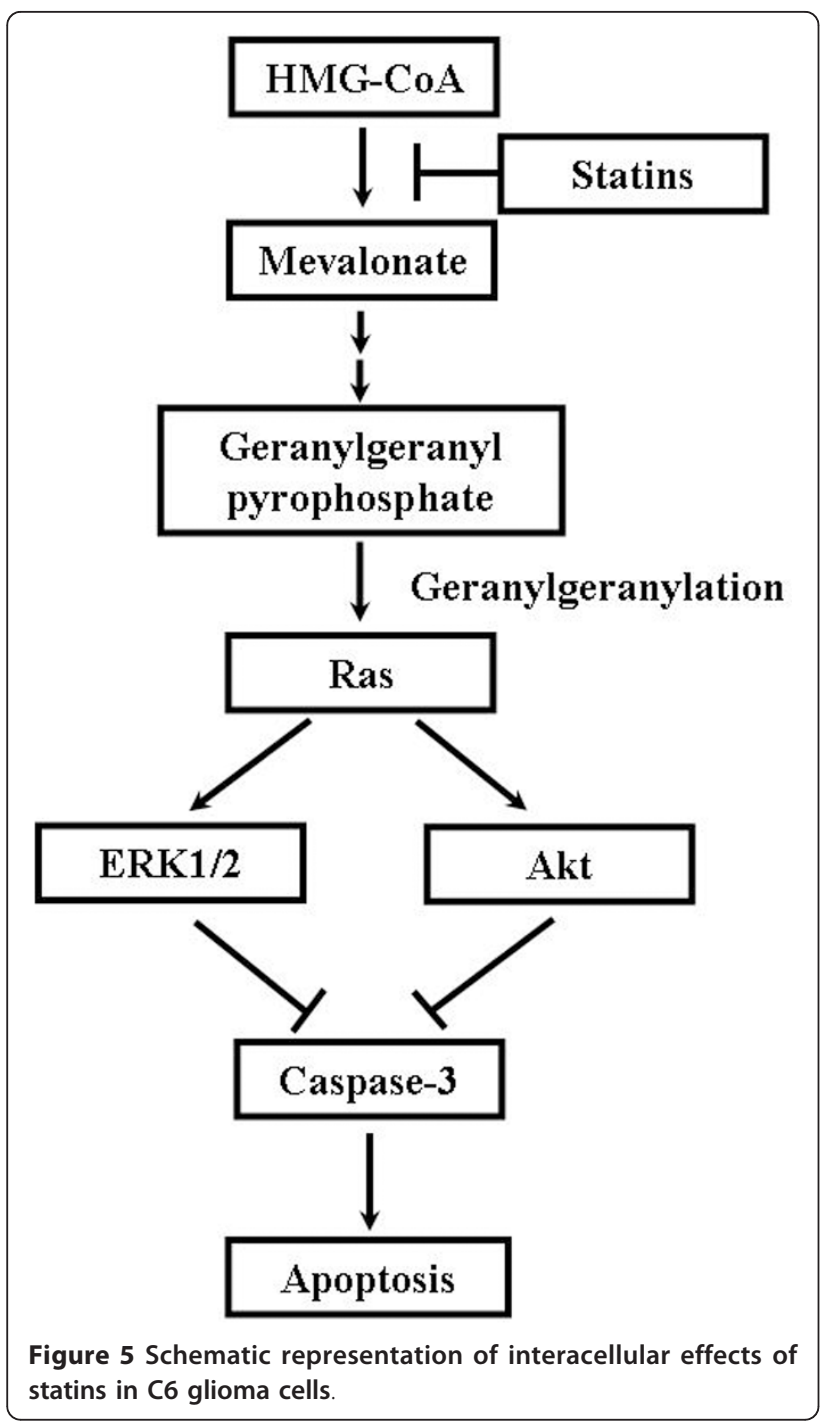

\section{Acknowledgements}

This work was supported by the High-Tech Research Center Project for Private Universities and a matching fund subsidy from MEXT (Ministry of Education, Culture, Sports, Science and Technology), Japan, 2007-2011.

\section{Author details}

'Division of Pharmacotherapy, Kinki University School of Pharmacy, Kowakae, Higashi-Osaka 577-8502, Japan. ²Department of Pharmacy, Sakai Hospital, Kinki University School of Medicine, Sakai, Osaka 590-0132, Japan. ${ }^{3}$ Department of Pathology, Kinki University School of Medicine, Osakasayama, Osaka 589-8511, Japan. ${ }^{4}$ Department of Surgery, Kinki University School of Medicine, Osakasayama, Osaka 589-8511, Japan. ${ }^{5}$ Department of Pharmacy, Kinki University Hospital, Osakasayama, Osaka 589-8511, Japan.

\section{Authors' contributions}

MY and MT carried out cell viability assay, caspase-3 activity assay, statical analysis, and drafted the manuscript. TS, TI, MI, and YY carried out western bolotting analysis. TS, TI, and Ml contributed to statistical analyses. SN designed the experiments and revised the manuscript. All authors read and approved the final manuscript.

\section{Competing interests}

The authors declare that they have no competing interests.

Received: 9 May 2011 Accepted: 10 August 2011

Published: 10 August 2011

\section{References}

1. DeAngelis LM: Brain tumors. N Engl J Med 2001, 344:114-123.

2. Reardon DA, Wen PY: Therapeutic advances in the treatment of glioblastoma: rationale and potential role of targeted agents. Oncologist 2006, 11:152-164.

3. Nishida S, Matsuoka H, Tsubaki M, Tanimori Y, Yanae M, Fujii Y, Iwaki M: Mevastatin induces apoptosis in HL60 cells dependently on decrease in phosphorylated ERK. Mol Cell Biochem 2005, 269:109-114.

4. Tsubaki M, Yamazoe Y, Yanae M, Satou T, Itoh T, Kaneko J, Kidera Y, Moriyama K, Nishida S: Blockade of the Ras/MEK/ERK and Ras/PI3K/Akt pathways by statins reduces the expression of bFGF, HGF, and TGF- $\beta$ as angiogenic factors in mouse osteosarcoma. Cytokine 2011, 54:100-107.

5. Wu J, Wong WW, Khosravi F, Minden MD, Penn LZ: Blocking the Raf/MEK/ ERK pathway sensitizes acute myelogenous leukemia cells to lovastatininduced apoptosis. Cancer Res 2004, 64:6461-6468.

6. Jiang Z, Zheng X, Lytle RA, Higashikubo R, Rich KM: Lovastatin-induced up-regulation of the BH3-only protein, Bim, and cell death in glioblastoma cells. J Neurochem 2004, 89:168-178.

7. Koyuturk M, Ersoz M, Altiok N: Simvastatin induces proliferation inhibition and apoptosis in $\mathrm{C} 6$ glioma cells via c-jun $\mathrm{N}$-terminal kinase. Neurosci Lett 2004, 370:212-217.

8. Fujiwara K, Tsubaki M, Yamazoe Y, Nishiura S, Kawaguchi T, Ogaki M, Nishinobo M, Shimamoto K, Moriyama K, Nishida S: Fluvastatin induces apoptosis on human tongue carcinoma cell line HSC-3. Yakugaku Zasshi 2008, 128:153-158.

9. Bouterfa HL, Sattelmeyer V, Czub S, Vordermark D, Roosen K, Tonn JC: Inhibition of Ras farnesylation by lovastatin leads to downregulation of proliferation and migration in primary cultured human glioblastoma cells. Anticancer Res 2000, 20:2761-2771.

10. Cerezo-Guisado Ml, García-Román N, García-Marín L, Alvarez-Barrientos A, Bragado MJ, Lorenzo MJ: Lovastatin inhibits the extracellular-signalregulated kinase pathway in immortalized rat brain neuroblasts. Biochem J 2007, 401:175-183.

11. Taylor-Harding B, Orsulic S, Karlan BY, Li AJ: Fluvastatin and cisplatin demonstrate synergistic cytotoxicity in epithelial ovarian cancer cells. Gynecol Oncol 2010, 119:549-556.

12. Lee MV, Fong EM, Singer FR, Guenette RS: Bisphosphonate treatment inhibits the growth of prostate cancer cells. Cancer Res 2001, 61:2602-2608.

13. Shipman CM, Rogers MJ, Apperley JF, Russell RG, Croucher PI: Bisphosphonates induce apoptosis in human myeloma cell lines: a novel anti-tumour activity. Br J Haematol 1997, 98:665-672

14. Morgan MA, Sebil T, Aydilek E, Peest D, Ganser A, Reuter CW: Combining prenylation inhibitors causes synergistic cytotoxicity, apoptosis and disruption of RAS-to-MAP kinase signalling in multiple myeloma cells. $\mathrm{Br}$ J Haematol 2005, 130:912-925.

15. Tsubaki M, Kato C, Nishinobo M, Ogaki M, Satou T, Ito T, Kusunoki T, Fujiwara K, Yamazoe Y, Nishida S: Nitrogen-containing bisphosphonate, YM529/ONO5920, inhibits macrophage inflammatory protein 1 alpha expression and secretion in mouse myeloma cells. Cancer Sci 2008, 99:152-158.

16. Park IH, Kim JY, Jung JI, Han JY: Lovastatin overcomes gefitinib resistance in human non-small cell lung cancer cells with K-Ras mutations. Invest New Drugs 2010, 28:791-799.

17. Horiguchi A, Sumitomo M, Asakuma J, Asano T, Asano T, Hayakawa M: 3hydroxy-3-methylglutaryl-coenzyme a reductase inhibitor, fluvastatin, as a novel agent for prophylaxis of renal cancer metastasis. Clin Cancer Res 2004, 10:8648-8655.

18. Sondergaard TE, Pedersen PT, Andersen TL, Søe K, Lund T, Ostergaard B, Garnero P, Delaisse JM, Plesner T: A phase II clinical trial does not show that high dose simvastatin has beneficial effect on markers of bone turnover in multiple myeloma. Hematol Oncol 2009, 27:17-22.

19. Skottheim IB, Gedde-Dahl A, Hejazifar S, Hoel K, Asberg A: Statin induced myotoxicity: the lactone forms are more potent than the acid forms in human skeletal muscle cells in vitro. Eur J Pharm Sci 2008, 33:317-325. 